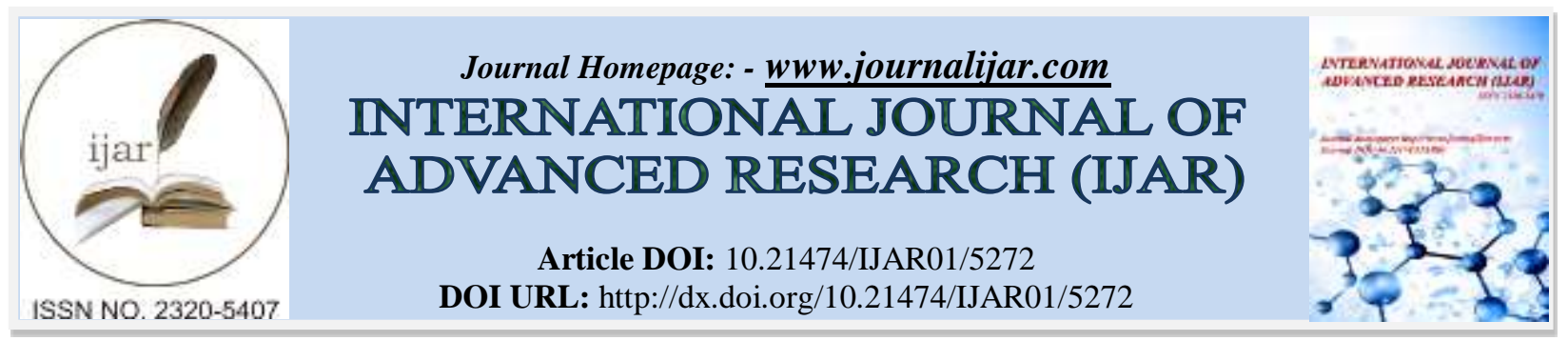

RESEARCH ARTICLE

\title{
EDUCATIONAL STATUS OF POPULATION WITH DISABILITY IN PUNE DISTRICT OF MAHARASHTRA, INDIA.
}

Vini Sivanandan Vinaya Sivanandan.

Population research Centre, Gokhale Institute of Politicsand Economics.

\section{Manuscript Info}

Manuscript History

Received: 24 June 2017

Final Accepted: 26 July 2017

Published: August 2017

Key words:-

Disability; Education; Age.

\begin{abstract}
The city of Pune is known as the educational capital of Maharashtra, and boast itself, as the student city. However, it remains to see whether the same infrastructure or opportunity is available to the population with disability further if available, whether it is equivalently accessible across all types of the disability. The aim of this paper is first to estimate the prevalence of disability by its types and second is to examine the representation of the population by types of disability. For our study the population with disability of Pune in the age group 15-19 years from Census, 2011 were considered for our study. The majority of the population with disability who are attending an educational institute belongs to disability type seeing, hearing, speech and any other type of disability. Overall, the percentage of the population attending an educational institute starts showing a decline from age 17 onwards. Nearly half the proportion of the population with disability type mental retardation has never attended any educational institutes. It may be the limitation of conventional education, but at least the focus should be on to bring the population with disability type mental retardation in other types of training.
\end{abstract}

Copy Right, IJAR, 2017,. All rights reserved.

\section{Introduction:-}

Every individual has an enormous potential what it needs is self-realization of its potential and a conducive atmosphere to demonstrate its skill. Motivation along with a supportive system can bring out the best in an individual and the absence of it only creates an atmosphere of underutilized resources and a vacuum in an individual's life.

Here the role of education with all its limitation gives an exposure and identifies an individual with certain skills. It further provides direction to an individual to upgrade his/her skills in reshaping the future of an individual and ultimately the society. Although, education may not cover all the skill required or trains an individual and identify his or her hidden skill but no one can deny that exposure of education is his or her first step in learning towards the challenges and the diversity of the society. Education is an ongoing process and if provided systematically helps an individual growth. 
The ability of a system to create an education system catering to the need of diverse population is a challenge in itself. It is and will be an ongoing process which revolve as per the requirement of a diverse population and changing society.

Educational requirement of the population with disability is a complex one which needs to be updated as per the changing society and the type of disability. For example, the educational needs of population with disability type mental retardation is not same as the educational needs of population with disability type mental illness. Hence, the question arises in what way the educational system caters to the need of the population with different types of disability. Moreover, whether the existing system caters and incorporates to the present need of the population with all types of disability and if so what is the level of their awareness among the population with disability.

The United Nations Convention on the Rights of Persons with Disabilities (CRPD), adopted in 2006, aims to "promote, protect and ensure the full and equal enjoyment of all human rights and fundamental freedoms by all persons with disabilities, and to promote respect for their inherent dignity”. According to the World Health Survey around 785 million (15.6\%) persons 15 years and older live with a disability, while the Global Burden of Disease estimates a figure of around 975 million (19.4\%) persons. Of these, the World Health Survey estimates that 110 million people $(2.2 \%)$ have very significant difficulties in functioning, while the Global Burden of Disease estimates that 190 million (3.8\%) have "severe disability" - the equivalent of disability inferred for conditions such as quadriplegia, severe depression, or blindness (World Health Organization 2012).

The number of people with disabilities is growing. This is because populations are ageing - older people have a higher risk of disability - and because of the global increase in chronic health conditions associated with disability, such as diabetes, cardiovascular diseases, and mental illness (World Health Organization 2012).

Patterns of disability in a particular country are influenced by trends in health conditions and trends in environmental and other factors - such as road traffic crashes, natural disasters, conflict, diet, and substance abuse. School enrolment rates differ among impairments, with children with physical impairments generally faring better than those with intellectual or sensory impairments. Those most excluded from the labour market are often those with mental health difficulties or intellectual impairments (World Health Organization, 2012).

\section{Background:-}

The city of Pune is known as the educational capital of Maharashtra or Cambridge of the east, and boast itself, as the student city. Apparently, because of availability of infrastructure, whether the same infrastructure or opportunity is available to the population with disability is a matter of concern. If available, whether it is equivalently accessible across all types of population with disability. Census of India, 2011 identifies eight types of disability voice: Seeing, Hearing, Speech, Movement, Mental Retardation, Mental Illness, Any Other disability and Multiple disability. Availability and accessibility of resources are reflected in the educational status of an individual. As per Census 2011 around 2 percent (26.8 million) of the total population in India suffers from disabilities. In Pune UA the number of the population with disability in the age group 5-19 is 25087 .

The aim of the present study is to examine the opportunity available to the population with various disabilities in Pune UA in terms of representation in higher education institutions.

\section{Research Findings:-}

Here, we considered the population with disability in the age group 5-19 years of age and their educational status. Age group 5-19 years were considered mainly we expect in this age group the student to be attending educational institutes or at least complete a matriculation.

Educational status in Census of India, 2011 is divided into two main groups of attending and not attending an educational institute. Further, not attending education institutes, is divided as attended educational institute earlier and never attended educational institute.

The figure below presents the distribution of the population with disability by types of disability and by educational status. The representation of different types of the disabled population of the respective type of education was 
calculated and given below. The population in the age group 17-19 years who never attended an educational institute is 664 and is largely represented by disability type mental retardation (32\%) and to an extent, disability type Multiple disability (14\%), and In a speech (13.4\%). Around 1580 population in the age group 17-19 years had attended an educational institute earlier and now is not attending any educational institute. In this group approximately 20 percent of each is represented by disabled type hearing, spoken communication and any other type of impairment. This infers, substantial numbers of the disabled population are not going in for higher education. It needs to be examined whether it is due to lack of infrastructure or lack of awareness which holds back these students. Population with disability who is attending an educational institute is 5680 and the majority of them are from disability type seeing, hearing, speech and any other type of disability.

Figure 1:- Percent Distribution of Disabled population by types of disability an educational status in, Pune 2011

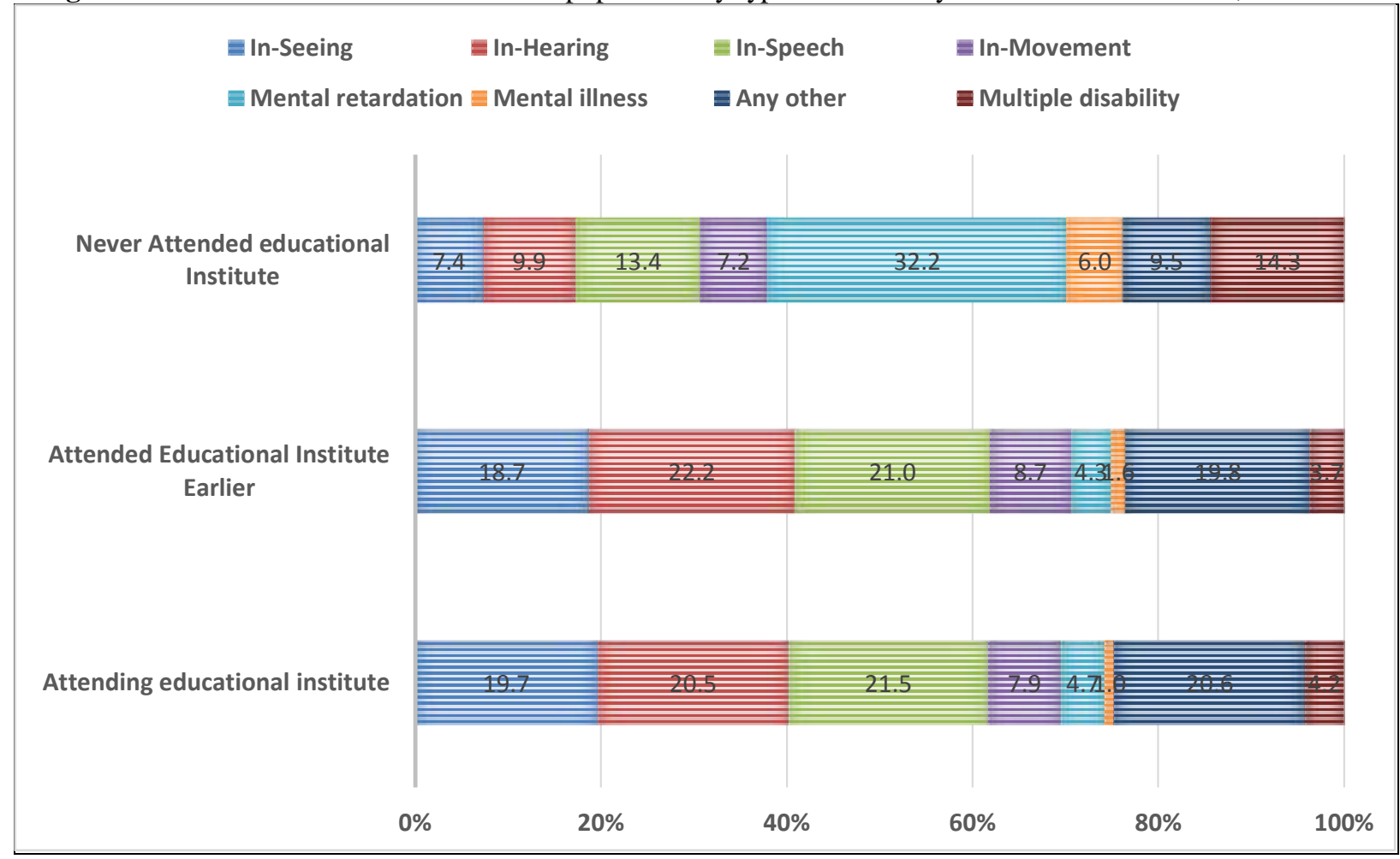

Source: Unit data from Census of India, 2011

We were interested in knowing the continuity of education. Census of India, 2011 gives information of those not attending an educational institute into two groups as never attended any educational institute and attended an educational institute before. Population with disability in any age group is due to identification and acceptance of disability, born disabled and decrease in the number of population with disability due to mortality, migration (which might be very less), and cured from disability.

Broadly speaking, it is assumed that education up to grade 10 or age 16 access to education is comparatively better than access to education in the age group 17-19 years of age. 
Figure 2:- Percent Distribution of Disabled population by educational status in, Pune 2011

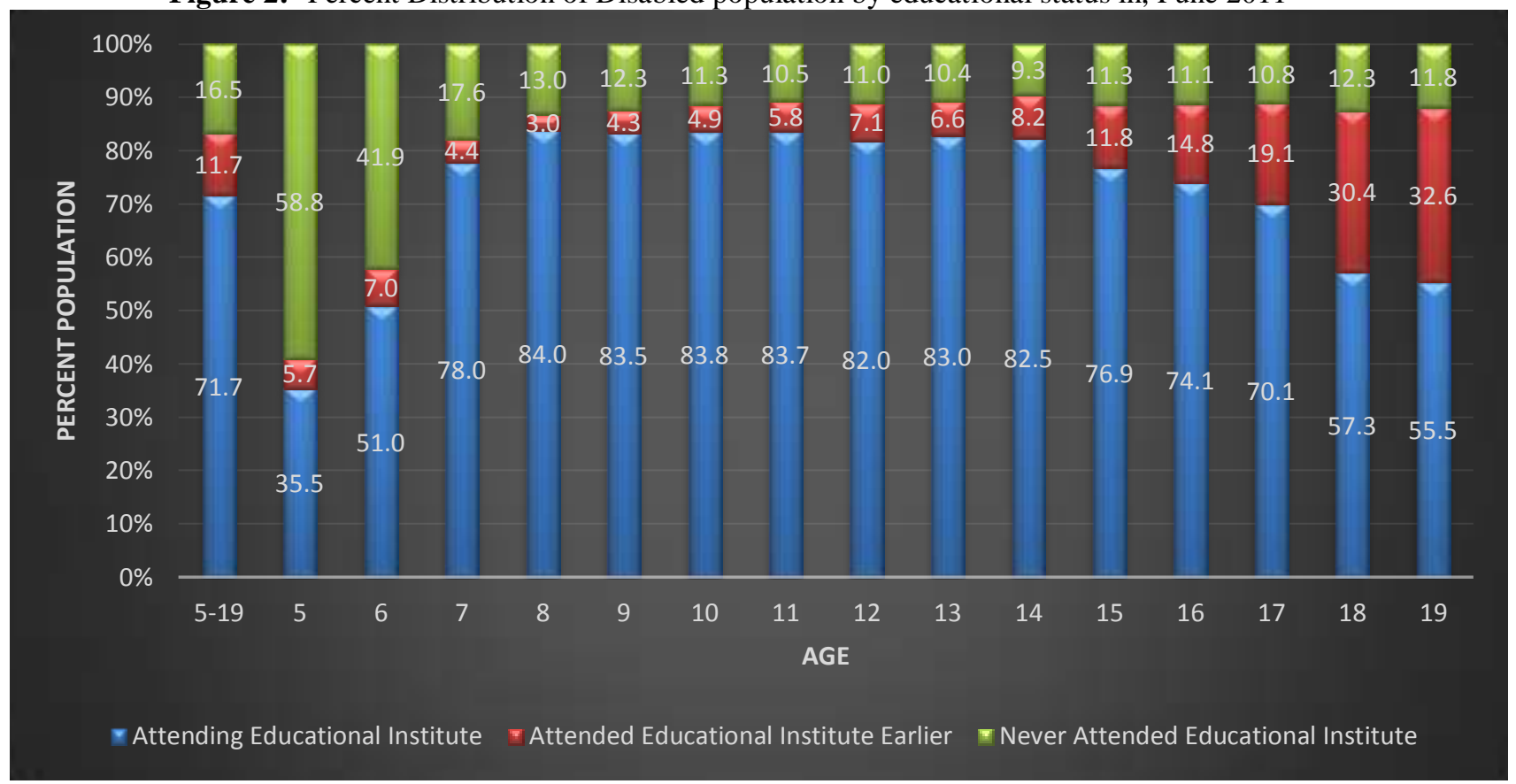

Source: Unit data from Census of India, 2011

As noted from the above figure among the total population with disability in the age group 5-19 years of age, 71 percent of the total population with disability is going to an educational institute whereas 16 percent of the total population with disability never attended any educational institute. Approximately 11 percent of the population with disability, in the age group 5-19 years, had earlier attended educational institute and now are not attending any educational institutes. This implies, if these 11 percent of the total educated population if had continued with education, 82 percent would have been attending the educational institute.

Further, we anticipate in early age, there might be a delay in initiation of attending an educational institute, especially after the detection of disability the time needed from parents/caretakers to explore the educational institutes that caters and suits the population with disability. In summation, there might be a handicap, which might have passed as one becomes older or severity of disability created a restriction in continuity of education. Hence, we tested to explore the educational status of education by each age starting from age 5 up to age 19.

As expected at the age of five only 35 percent of the total population with disability were attending an educational institute, which is 51 percent in the age 6 , and 78 percent in the years 7 . In the age group 8-14 years $82-84$ percent of the population with disability in the respective age group (8-14 years) were attending educational institutes. The proportion attending educational institutes among the total is 76 percent at age 15 to 55 percent in age 19 . The maximum difference in the percent of the population with disability attending educational institutes of 13 percent as compared to the previous age 17 years (70\%) is observed at age 18 years (57\%). Presumably, this is the age at which one enters higher education.

About 10 to 11 percent of the total population with disability never attended any educational institutes if we exclude the ages 5, 6 and 7. Whereas, those who had earlier attended educational institute and are now not attending any educational institutes is more or less in the range of 3 to 4 percent.

The highest percent of the population who earlier were attending an educational institute and now not attending educational institutes is observed in the age 18 and 19 consisting of 30 and 32 percent of the population in the respective age. 
Types of disability to an extent affects the educational status. For example, the education status of the population with disability by disability type multiple disability, mental retardation and mental illness, movement varies from the educational status of disability type seeing, hearing and speech. Each of the population with disability by type of disability, needs special education catering to their needs and future prospects mainly in terms of employment.

Moreover, it is extremely likely that some types of impairment are not acquired by birth, but happened as age progresses, such as disability type mental illness, multiple disability, movement mainly due to accident, family condition and tension.

Hence, we further explore and investigate the educational status by type of disability and by age.

Disability type seeing has a braille letter which is helpful in undergoing education and attending an educational institute but whether it is uniformly accessible across age needs to be investigated.

The figure gives the educational status at each age by disability type seeing. There are 4633 populations with disability in Pune with disability type seeing.

Figure 3:- Percent Distribution of Population with seeing disability and by educational status in, Pune 2011

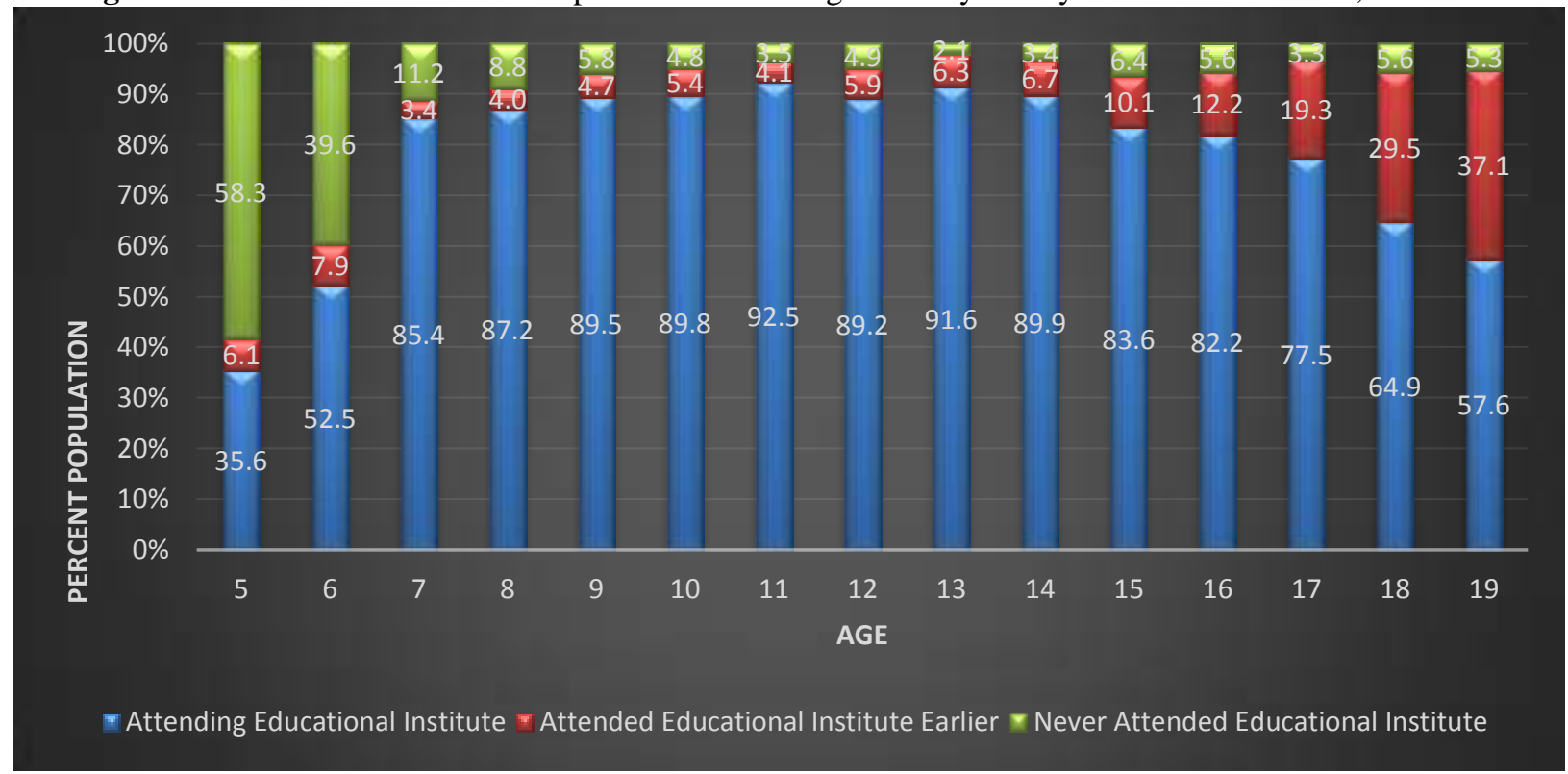

Source: Unit data from Census of India, 2011

Population with disability, with disability type seeing, shows the same trend of the population with disabilities in terms of educational status and by age. The population with the type of disability, seeing has maximum percent of the population at the age 11 with 92 percent of the disabled population by disability type seeing are attending an educational institute and is 57 percent in the age 19 a slightly better representation as compared to the total population with disability attending an educational institute at age 19. The representation at the age 7 in a population with disability type seeing was the maximum with $85 \%$, with a difference of $33 \%$ from age 6 .

As observed in population with disability, the percentage of the population attending an educational institute starts showing a decline from age 17. Subsequently, the percentage of the population with disability type seeing who attended educational institute earlier at age 17 is (19\%) and in age 18 (29\%). This indicates, most of the dropout happens from age 17 to age 18.

The figure gives the educational status at each age by disability type hearing. There are 5174 populations with disability in Pune with disability type hearing. 
Figure 4:- Percent Distribution of Population with Hearing disability and by educational status in, Pune 2011

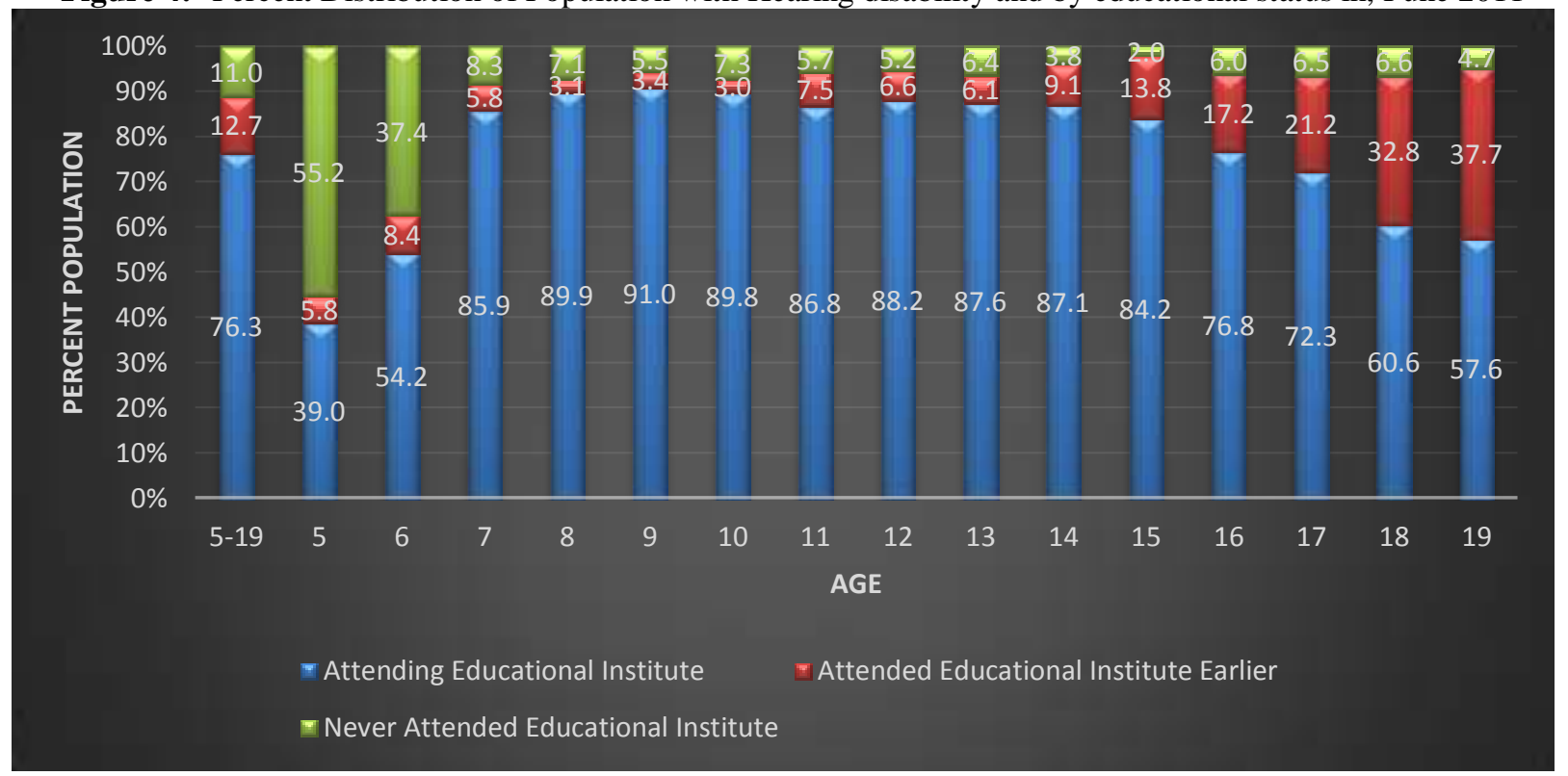

Source: Unit data from Census of India, 2011

Education for population with disability type hearing can be achieved with the help of learning aids. The percent of the population with disability type hearing and attending educational institute increases as age increases and attains its maximum of 91 percent at age 9 and remain stable in the range of 80 to 85 percent till age 16 . The decline in the population attending educational institute starts from age 16 and the maximum decline as observed with other types of disability happens in age 18 with $60 \%$ as compared to age 17 with 72 percent a difference of almost 12 percent. Subsequently the percent of the population who had attended an educational institute earlier and now not attending any educational institute also increased to 12 percent in the age $17(21 \%)$ and age $18(32 \%)$.

Figure 5:- Percent Distribution of Population with Speech disability and by educational status in, Pune 2011

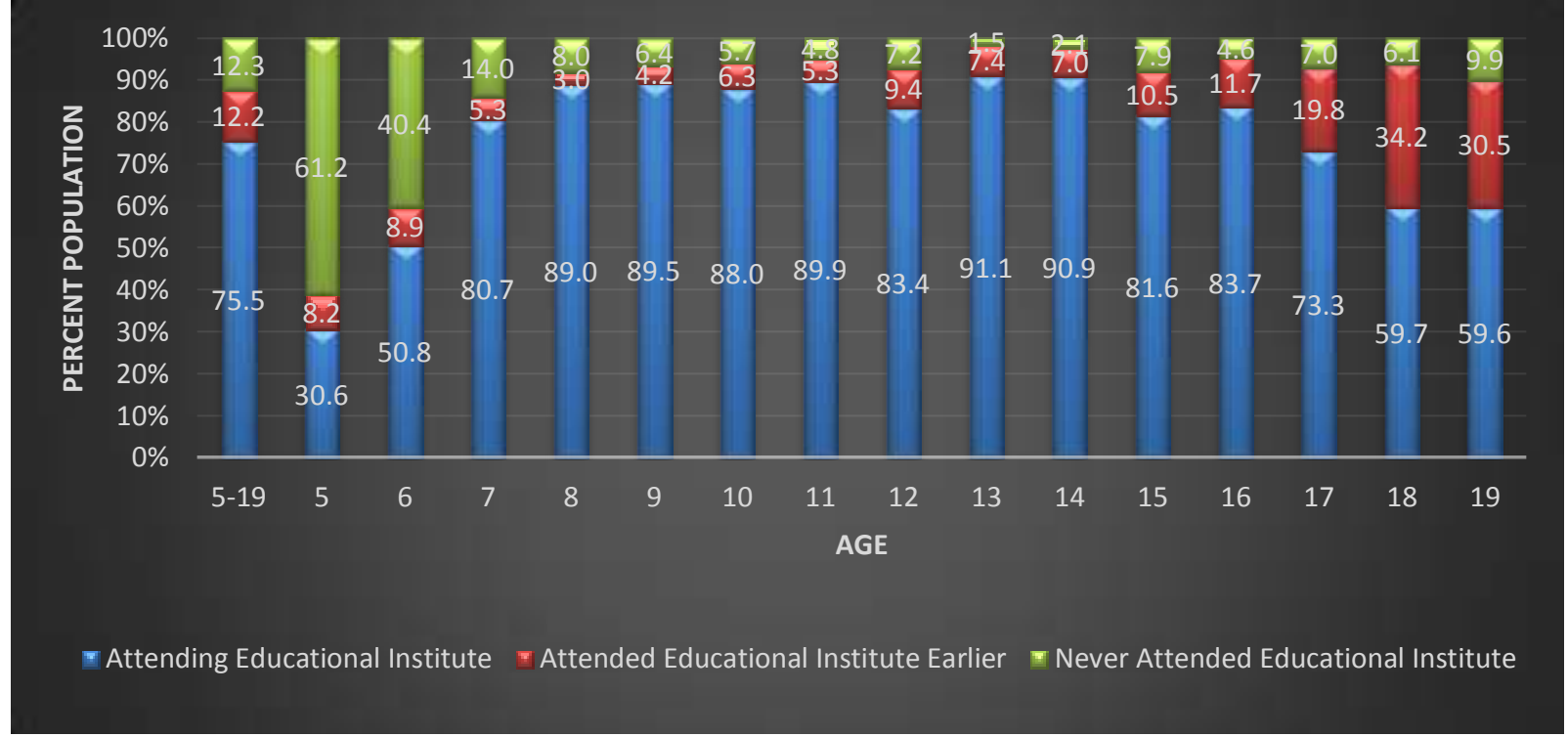

Source: Unit data from Census of India, 2011

There are 5100 population in the age group 5-19 with disability type speech. As noted in another type of disability the percent of population with disability type speech and attending educational institutes increases as age increases and reaches its maximum at age 13 with $91 \%$. The decline in the percent of population with speech and attending 
educational institutes starts from age 16 and attains its maximum decline in age 18 of 59 percent a difference of 13 percent from age 17 of $73 \%$. Subsequently, there is an increase of 15 percent of the population with disability with disability type speech from age 17 to age 18 .

Figure 6:- Percent Distribution of Population with Movement disability and by educational status in, Pune 2011

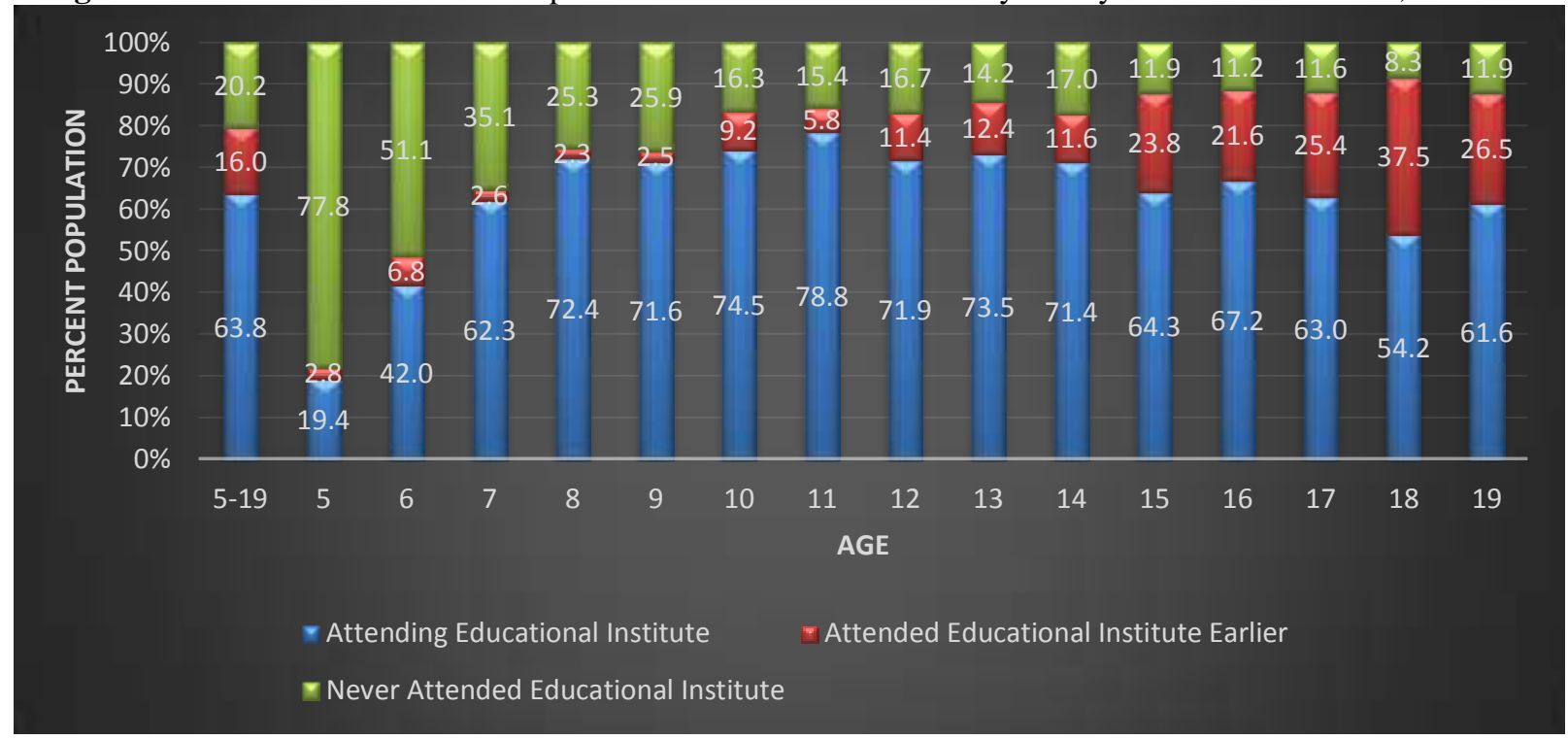

Source: Unit data from Census of India, 2011

There are 1654 population with disability with disability type movement in the age group 15-19. Here the number of the population with disability in age 17 of 138 is almost double to as the number of the population with disability in age 5 of 72. Comparatively the disability type movement who is attending educational institutes is only 19 percent at age 5 as compared to 30 percent as observed in other cases of disability and total disabled population. The proportion of population with disability with disability type movement and seeing an educational institute is maximum at the age 11 with 78 percent, which is less than almost 10 percent as observed in other cases of disability and total population with disability. Here also, the maximum decline in terms of proportional of population attending an educational institute is maximum at age 18 with only 54 percent of the population with disability type movement and attending educational institutes as compared to 63 percent of the total disabled with disabled type movement at age 17. Significant decrease in proportion of the population attending an educational institute is also observed in age 15 with 64 percent as compared to age 14 with 71 percent.

The proportion of population with disability who attended educational institute earlier and now is not attending an educational institute is almost double in the age 10 where it is almost 9 percent not attending an educational institute as compared to 2 percent at age 9 . Further, at age 15 the proportion of population with disability who is not attending an educational institute is $23 \%$ percent at age 15 almost double compared to that at age 14 with 11 percent. Significant difference was also observed in age 18 with 37 percent of the proportion of the population with disability not attending educational institutes with disability type movement. Interesting contrast to what is observed in other types of disability the percent of population not attending an educational institute decreased to 26 percent as compared to 37 percent at age 18. Significantly the proportion of the population with disability with disability type movement and never attended an educational institute is slightly more than 10 percent, which is more than the total population with disability and other types of disability 9 seeing, Hearing, Speech) which are less than 10 percent. This indicates, the proportion of the population with disability type movement are comparatively finding it more difficulties in continuing with their education. 
Figure 7:- Percent Distribution of Population with Mental Retardation disability and by educational status in, Pune 2011

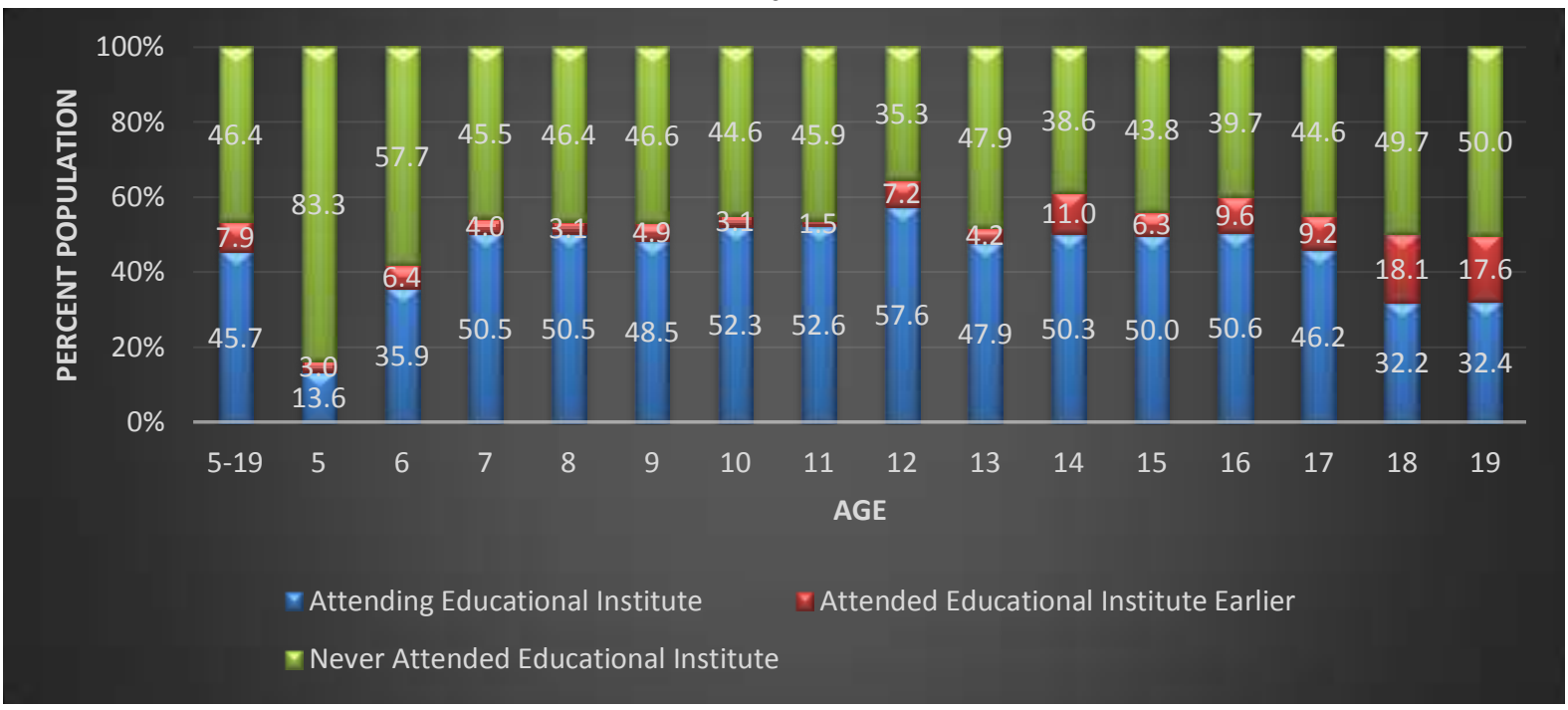

Source: Unit data from Census of India, 2011

There are 1881 population with disability type mental retardation in the age group 5-19. As observed in other types of disability the proportion of the population in each and in the total age 5-19 (45\%) is lower as compared to other types of disability. On an average only half or 50 percent of the disabled type mental retardation are attending educational institutions and the maximum percent of population with disability type mental retardation and attending an educational institute at age 12 is 57 percent. The decline in the percent of population attending educational institutes starts from age 17 with 46 percent as compared to 50 percent at age 16 . The maximum decline is observed in age 18 with just 32 percent of the total disabled population with disability type mental retardation attending an educational institute as compared to 46 percent at age 17 with a deviation of almost 14 percent.

Nearly half the proportion of the population with disability type mental retardation has never attended any educational institutes. The proportion of population with disability type mental retardation is almost double to 18 percent as compared to the age 17 with 9 percent for those who had attended an educational institute earlier and now is not attending an educational institute. This clearly indicates lack of resources and the disability type mental retardation are gravely underrepresented. It may be the limitation of conventional education, but at least the focus should be on to bring the population with disability type mental retardation in other types of training.

Figure 8:- Percent Distribution of Population with disability of Mental Illness and by educational status in, Pune 2011

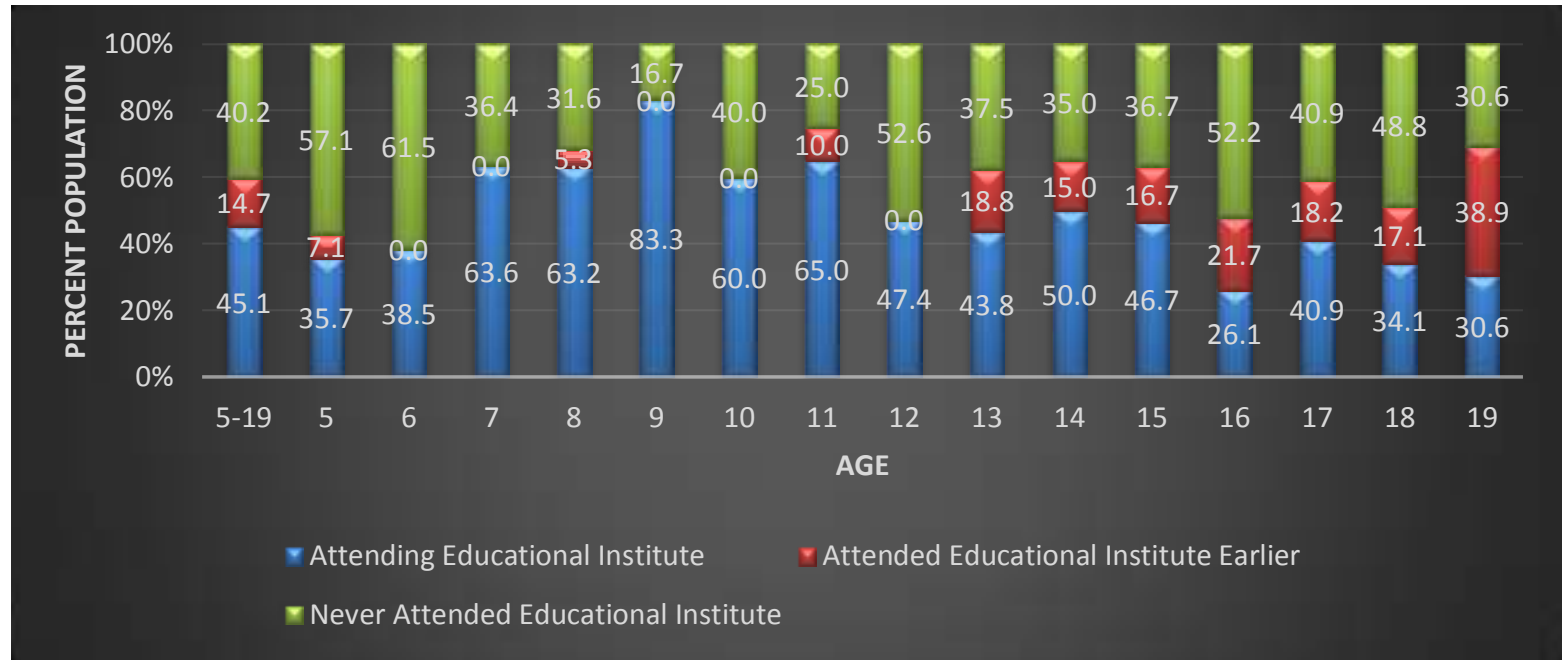


Source: Unit data from Census of India, 2011

There are 306 populations with disability type mental illness in the age group 15-19. This may be largely due to the identification and demonstrating the fact of the disabled population with disability type mental illness. This discrepancy in identification of mental illness is also contemplated in the proportion of the population who are attending an educational institution with a maximum of 83 percent of the total mental illness people attending an educational institute as compared to only 26 percent in age 16 . The proportion of the population attending educational institutes changes drastically from one age to another. Subsequently, the proportion of population with disability who never attended any educational institutes PR attended an educational institute before changes drastically.

Figure 9:- Percent Distribution of Population with disability of Any Other Illness and by educational status in, Pune 2011

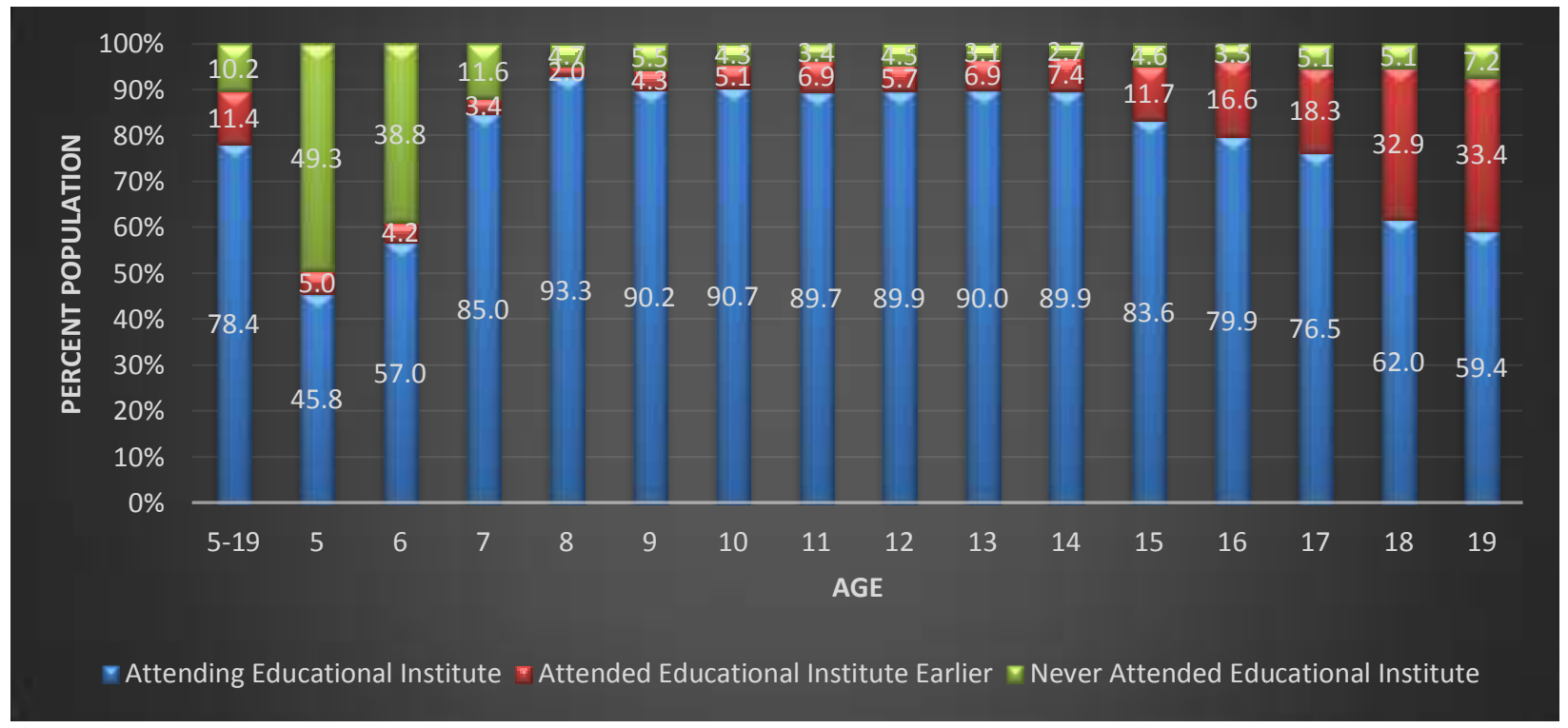

Source: Unit data from Census of India, 2011

There are 4992 populations with disability with disability type any other disability. Compared to other types of disability the proportion of population with disability who are attending educational institutes are higher and is highest in the age of 8 . As observed in the age group the proportion of population with disability who are attending an educational institute drastically comes down at age 18 with only 62 percent of the population with any other type disability attending educational institutes as compared to 76 percent of the population with disability type any other. The proportion of populations with any other type of disability who attended educational institute earlier and is now not attending educational institutes highest in this age with 32 percent. 
Figure 10:- Percent Distribution of Population with Multiple disability and by educational status in, Pune 2011

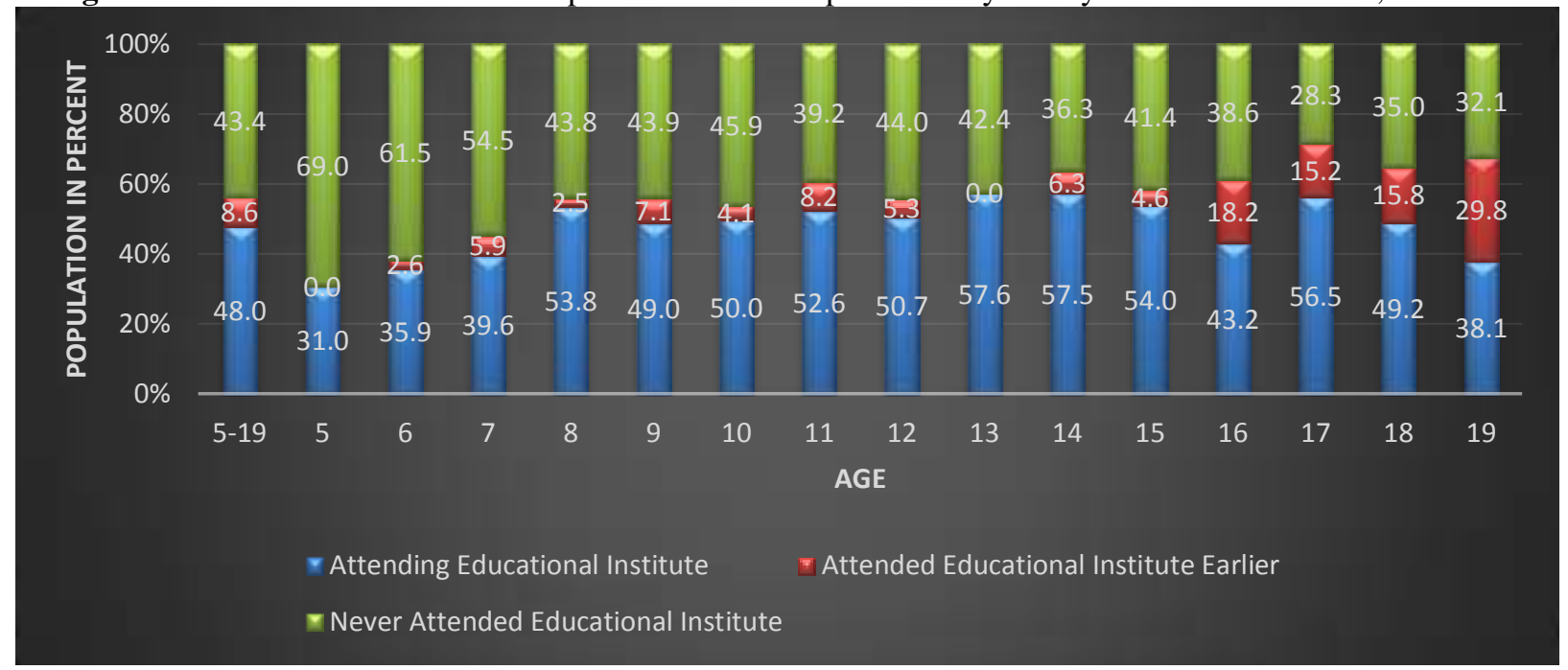

Source: Unit data from Census of India, 2011

There are 1347 populations with disability type multiple disability. As observed in disability type mental retardation the proportion of the population with disability who have never attended any educational institute is higher in this type of disability with almost 35 to 40 percent of the proportion of the population never attended any educational institute. Nearly 50 percent of the disabled type of multiple disability is attending an educational institute and at age 19 is only 38 percent.

\section{General Summary and Conclusion:-}

The present study was initiated to examine the representation of the population with various disabilities in education in terms of representation of age with respect to attendance and non-attendance of education.

Research Studies show that years of education are one of the important predictors of inclusion of people with disabilities into the work cycle, promoting employment opportunities and improving quality of life (Drake et al., 2000).

Representation of the population with disability in educational institutes, particularly in the age group 5-19 years not only reflects the accessibility but also the continuity of education. It is indeed encouraging that 71 percent of the population with disability in Pune in the age group 5-19 years of age are attending an educational institute, which is slightly more in the age group 8-14 years with 82-84 percent. However, the proportion of the population with disability attending an educational institute is only 55 percent in age 19. Notably, the percentage of the population who was earlier attending an educational institute and now not attending educational institutes is strikingly high with 30 percent from age 18 onwards. The maximum change of 13 percent as compared to the previous age 17 years (70\%) is noted at age 18 years $(57 \%)$.

From the findings, we observe a decrease in the representation of the population with disabilities moving from one level to another level in later year of education and assume it may be due to lack of supportive services and limited availabilityof various types of disabilities.

About 10 to 11 percent of the population with disability never attended any educational institutes if we exclude the ages 5, 6 and 7. Whereas, those who had earlier attended educational institute and are now not attending any educational institutes is more or less in the range of 3 to 4 percent.

This implies, the focus should be on the continuity of education of population with disability based on their needs and skill development. In addition, the challenge to catch up with the mainstream educational atmosphere which lays emphasis on time and measure people achievement based on excellence. 
The programme requires in depth research on educational and skill development by types of disability for the disabled population to be self sufficient.

Future research may scrutinize the development of population with disabilities by following up on their inclusion in graduate and post-graduate studies, and thereafter in work and in society. The present paper gives the distribution of representation of population with disabilities in one of the metropolitans city of India known for its educational institutions. If this is the situation in Pune we can very well imagine the status of remote corners and rural India which has a substantial population with disability. Hence, study concludes with a need to incorporate higher education institutions so that it is accessible to population with various types of disabilities.

\section{References:-}

1. Census of India. 2011. The First Report on Disability. Registrar General and Census Commissioner, New Delhi, India.

2. Drake, A. I., Gray, N., Yoder, S., Pramuka, M., \& Llewellyn, M. (2000). Factors predicting return to work following mild traumatic brain injury: A discrimination analysis. Journal of Head Trauma Rehabilitation, 15(5), 1103-1112

3. Groce NE, Trani JF. Millennium Development Goals and people with disabilities. Lancet 2009; 374: 1800-1. 26.

4. Hasanuzzaman M, Khan S. Disability and Access to Higher education in India. International Journal of Research Commerce Management 2011; 2(11): 107-10.

5. [5] Lang R. The United Nations Convention on the Right and Dignities for Persons with Disability: a Panacea for Ending Disability Discrimination? European Journal of Disability Research 2009; 3: 266-85.

6. Mishra, A K and Gupta, R. 2006. Disability Index: A Measure of Deprivation among Disabled. Economic and Political Weekly, Vol. 41 (38):4026-4029.

7. Mohan I, Tandon R, Kalra H, Trivedi JK. Disability Assessment in Mental Illnesses using Indian Disability Evaluation Assessment Scale (IDEAS). Indian Journal of Medical Research 2005; 121: 75963. 30: 1155-67.

8. Singh, S. (1999). Gender dimension of Physical Disability. Economic and Political Weekly, 1958-1958.

9. Thornicroft G. Shunned: Discrimination Against People with Mental Illness. Oxford: Oxford University Press, 2006.

10. Wiersma D, Wanderling J, Dragomirecka E, et al. Social disability in Schizophrenia: Its Development and Prediction over 15 years in Incidence Cohorts in Six European Countries. Psychology Medicine 2000;

11. World Bank. 2007. "People with Disabilities in India: from Communities to Outcomes" Human Development Unit South Asian Region. World Bank.

12. World Health Organization. 2002. "World Report of Disability". Geneva, Switzerland: Department of Gender and Women's Health, WHO.

13. World Health Organization. 2012. "World Report on Disability". Geneva, Switzerland: Department of Gender and Women's Health, WHO. 